\title{
Un vaso cerámico con decoración dionisíaca procedente de Sisapo-La Bienvenida (Ciudad Real) ${ }^{1}$
}

\author{
Carmen FERNÁNDEZ OCHOA (Universidad Autónoma de Madrid) \\ Mar ZARZALEJOS PRIETO (Universidad Nacional de Educación a Distancia-UNED)
}

\section{Resumen}

En este artículo estudiamos una pieza cerámica singular hallada en la antigua ciudad de Sisapo (La Bienvenida, Almodóvar del Campo, Ciudad Real). El vaso, de forma hemisférica y con decoración a molde, muestra en la pared exterior un tema relacionado con el thiasos dionisíaco y en el fondo interno un gorgoneion en forma de relieve aplicado. Además del encuadre estilístico de la decoración, abordamos el problema de su contexto tecnológico y productivo.

Palabras clave: Cerámica con relieves. Sisapo. Estilo neoático. Thiasos dionisíaco. Gorgoneion. Minería romana.

\section{Summary}

In this paper we study a remarkable ceramic piece found in ancient Sisapo (La Bienvenida, Almodóvar del Campo, Ciudad Real). The vase is a hemispherical and flat-bottomed bowl, its outer wall decorated with a moulded relief in which several figures depict the Dionysiac thiasos. A Gorgon head was also applied as a relief to the inner bottom of the vase. We study the stylistic aspects of the decoration and treat the problem of productive and technological context.

Keywords: Molded relief pottery. Sisapo. Neo-attic style. Dionysiac thiasos. Gorgoneion. Roman mining.

\section{INTRODUCCIÓN}

La pieza que estudiamos fue recuperada en el transcurso de las excavaciones arqueológicas realizadas durante la campaña del año 2000 en el yacimiento de La Bienvenida-Sisapo (Almodóvar del Campo, Ciudad Real). La excepcionalidad de este producto en el ámbito de las producciones cerámicas conocidas en esta capital minera nos ha animado a dedicar su estudio al Profesor Bendala, amigo, maestro e investigador entusiasta de los vehículos de difusión de la iconografía clásica sobre soportes diversos.

1 Esta aportación se ha realizado en el marco del proyecto HAR2008-04817/HIST: El paisaje minero antiguo en la vertiente norte de Sierra Morena (provincia de Ciudad Real) financiado por el Ministerio de Ciencia e Innovación y dirigido por M. Zarzalejos Prieto. Por su parte, el proyecto de excavaciones sistemáticas en La Bienvenida-Sisapo ha sido financiado por el órgano competente de la Junta de
Del vaso original, únicamente han llegado a nosotros trece fragmentos de distintos tamaños, exhumados en el viridarium o espacio ajardinado de la zona descubierta del peristilo de la domus de las Columnas Rojas. Esta vivienda fue construida en época tardoaugustea-tiberiana y abandonada en una fecha aún imprecisa del siglo III d.C., momento a partir del cual sus estancias, parcialmente arruinadas, serán objeto de reocupaciones puntuales y, ya en tiempos tardoantiguos, se convertirán en cantera de elementos constructivos ${ }^{2}$. Desde el punto de vista estratigráfico y como se

Comunidades de Castilla-La Mancha en colaboración con el SEPECAM.

2 De los trabajos que estamos llevando a cabo en los últimos años en esta domus se ha ido dando cuenta con carácter preliminar en varias publicaciones (Zarzalejos, Fernández Ochoa y Hevia, 2004; 2007 y 2011.). 
indicará después con mayor detalle, esta cerámica se ha recuperado en un estrato de derrumbe, por lo que desconocemos con certeza su contexto funcional de uso. Esta circunstancia adversa no nos ha disuadido de abordar su estudio individualizado, ya que, como advertíamos más arriba, se trata de un vaso singular dentro de los repertorios cerámicos del yacimiento, tanto por sus rasgos tecnológicos como por su concepto decorativo. Nuestro análisis se centrará en la técnica de realización y en el examen iconográfico y estilístico de sus representaciones, en un intento de encuadrar la pieza dentro de unos parámetros temporales y productivos acordes con estos segmentos informativos. Asimismo, nos ha parecido imprescindi- ble proceder a su caracterización arqueométrica, con el fin de abrir otra vía de conocimiento susceptible de ofrecer datos para la identificación de su ámbito geográfico de origen y del contexto tecnológico en el que se inscribe.

\section{DESCRIPCIÓN FORMAL Y OBSERVACIONES TÉCNICAS}

Se trata de un cuenco de base plana y perfil suavemente incurvado que remata en un borde de trayectoria recta y sección afilada, individualizado al exterior mediante una doble moldura cóncavo-convexa (fig.1). Su tamaño y calibre entran dentro de lo que cabría considerar un recipiente
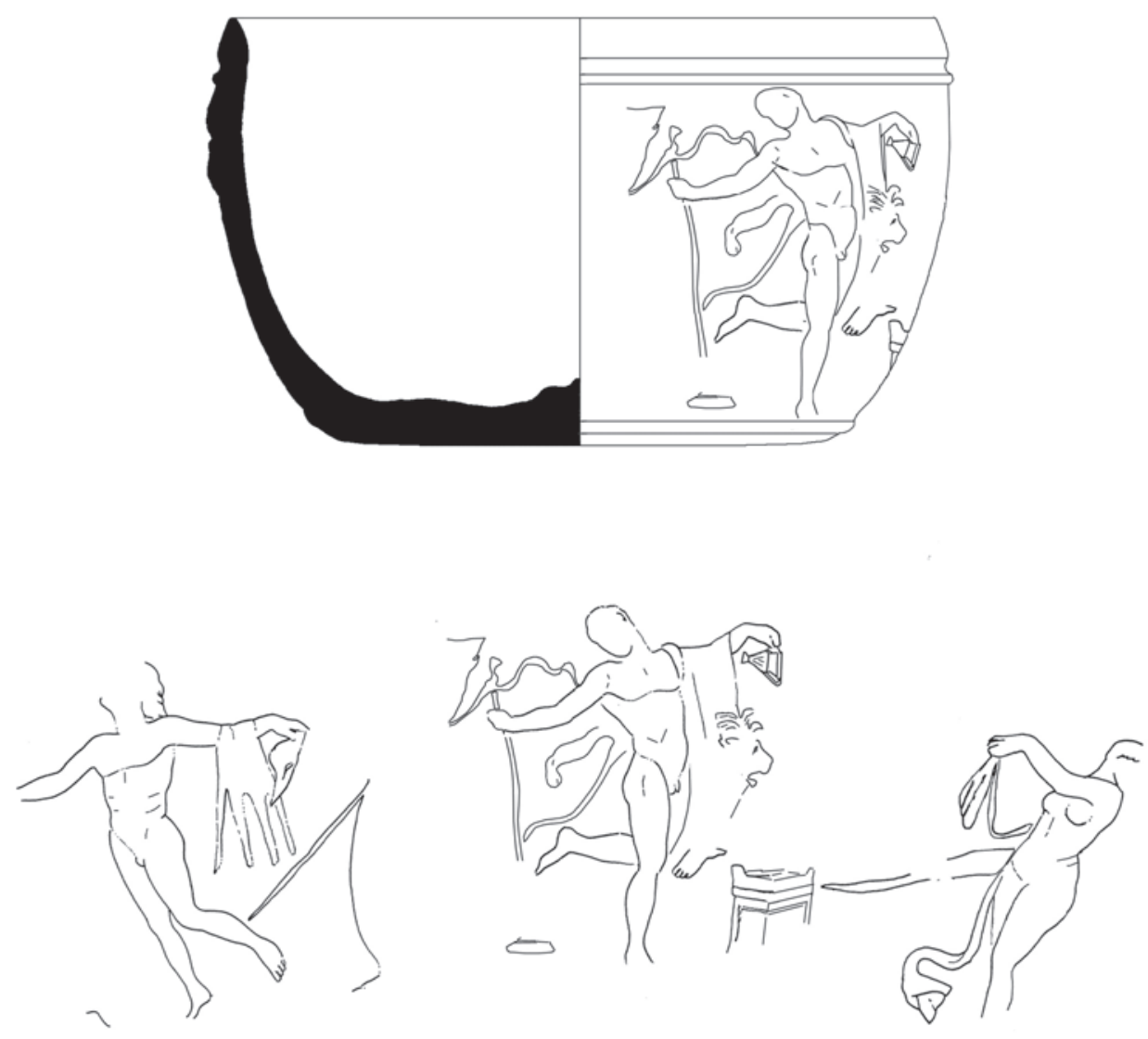

Figura 1. Representación gráfica del vaso 
de medianas proporciones, con 10,4 cm de diámetro en el borde, $7 \mathrm{~cm}$ de diámetro en la base y una altura de $6,3 \mathrm{~cm}$. Las paredes mantienen un espesor máximo de $5 \mathrm{~mm}$ que aumenta hasta los $7 \mathrm{~mm}$ en el fondo.

La pieza presenta en la superficie una coloración de tonalidad rojo muy pálido (M 27) ${ }^{3}$, que se intensifica ligeramente en la fractura (M 25). En su confección se empleó una arcilla muy depura$\mathrm{da}$, en la que apenas resultan visibles a simple vista diminutos puntos micáceos y alguna vacuola en la cara interna. La pasta cerámica es de consistencia semidura y presenta una fractura irregu- lar, algo bizcochada. La coloración de la pieza permite asegurar que fue cocida en ambiente oxidante y no se observan indicios de revestimiento engobe o barniz- en ninguna de sus superficies.

La decoración de la pared exterior se obtuvo mediante el empleo de un molde. De hecho, en la superficie interna se aprecian nítidamente las huellas dejadas por el alfarero al presionar la arcilla sobre la matriz para conseguir una mejor reproducción de los motivos durante el proceso de regularización del vaso en el torno (fig.2.1). El resultado es un relieve de cierta calidad plástica, aunque se aprecian diferentes defectos de impre-

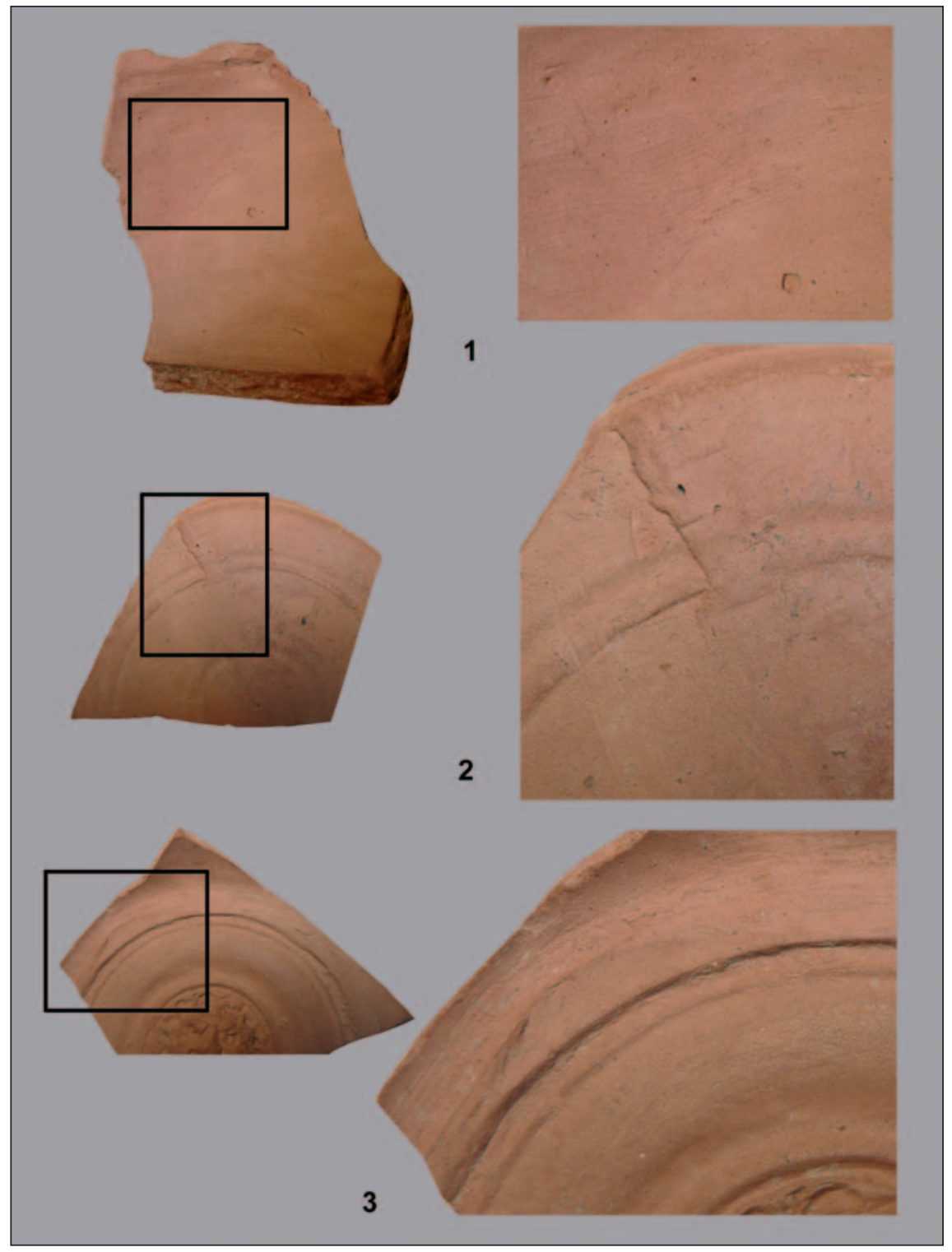

Figura 2. Observaciones sobre la técnica de ejecución del vaso

3 Para la descripción cromática se ha empleado el Code des couleurs des sols de A. Cailleux, Boubée, París. 
sión que afectan a ciertos detalles representativos, como se irá indicando en su momento oportuno. Del mismo modo, en algunas partes de la superficie del vaso se percibe una cierta rugosidad de la pared, cercana al craquelado, posiblemente debida al empleo de una masa de arcilla en estado demasiado sólido y al hecho de no haber sometido la superficie a ningún tratamiento en fresco tras el desmolde.

Asimismo, en el fondo externo se aprecia el espatulado incompleto de una rebaba de desarrollo lineal, lo que induce a pensar que el vaso pudo ser confeccionado con un molde bivalvo ${ }^{4}$ (fig.2.2).

En el fondo interno, el vaso presenta una decoración aplicada en forma de medallón central figurado, que fue fijado en su lugar con la ayuda de un instrumento de punta roma sobre el barro aún fresco tal y como se percibe en las huellas dejadas por este objeto alrededor del motivo aplicado. El medallón aplicado se inscribe en un doble círculo, cuya línea exterior se enmarca por una suave moldura convexa, que ha sido parcialmente desdibujada por los dedos del alfarero al regularizar la unión entre el fondo y el arranque de la pared (fig.2.3).

Todo ello estaría apuntando un cierto descuido en el proceso de realización del vaso, que podría ser indicativo tanto de su producción en un contexto altamente estandarizado donde prima la cantidad sobre la calidad del producto final, como de todo lo contrario, esto es, de su producción en un ámbito artesano más restringido y técnicamente menos experimentado.

\section{LA DECORACIÓN Y SU ENCUADRE ICONO- GRÁFICO Y ESTILÍSTICO}

La pared externa desarrolla un tema decorativo concebido a la manera de un friso corrido, delimitado en la zona superior por la doble moldura cóncavo-convexa, de la que arranca el borde del vaso y en la inferior por una moldura de sección cóncava, que anticipa y realza la base. Los fragmentos conservados permiten identificar tres figuras en actitud de danza, inequívocamente relacionadas con el thiasos dionisíaco. Debieron formar parte de una escena más amplia, integrada

4 Compartimos con J. M. Jerez Linde esta apreciación, al tiempo que le agradecemos sus observaciones sobre la por un cuarto personaje o, en su defecto, un objeto o elemento de buen tamaño, tal y como se intuye a partir de los indicios visibles entre las figuras $n^{\circ} 1$ y 2 .

La primera representación -figura $n^{\circ} 1$ - corresponde a un personaje masculino desnudo, pasante a la izquierda y con los brazos alzados, que se apoya sobre la pierna derecha mientras dobla ligeramente la izquierda (fig.3.1). La cabeza fue objeto de una impresión defectuosa que impide el reconocimiento de sus facciones, pero se puede apreciar que está girada hacia atrás y mirando hacia arriba, y hasta podría decirse que el personaje poseyó una oreja grande y puntiaguda o bien una cabellera poblada que alcanza con soltura el hombro. Sobre su antebrazo izquierdo descansa una piel de cuadrúpedo, muy probablemente perteneciente a una cabra, atributo éste que, sumado a las anteriores observaciones, invita a suponer que se trata de un sátiro representado en pleno éxtasis dionisíaco. La piel de cabra o nébrida suele ser, en efecto, un elemento relacionado con los sátiros, que se hizo frecuente en las representaciones del clasicismo griego y puede considerarse una reminiscencia de la naturaleza animal de estos seres en los tiempos arcaicos (Daremberg y Saglio, 1875-1919, IV-2: 1093). En época romana será también bastante usual la representación de sátiros con una piel de cabra cubriendo su torso, como sucede en una escultura procedente de Montemayor (Córdoba), fechada en el siglo II d.C., y que corresponde a un tipo reproducido con frecuencia en la plástica romana (Luzón y León, 1971: 244). En todo caso, la cabra es uno de los animales relacionados con el culto de Dionisos, ámbito en el que suele asociarse al rito del diasparagmos (LIMC, III-1: 415).

Entre esta figura y la siguiente $\left(n^{\circ} 2\right)$ se aprecian indicios de otra representación (fig.1). Podría aventurarse que fuera un ánfora o un recipiente de gran tamaño de cuerpo panzudo y boca acampanada. En tal caso, se trataría de un objeto directamente relacionado con el consumo de vino ligado al ritual dionisíaco, cuya presencia resultaría coherente con la naturaleza de la escena representada.

La figura $\mathrm{n}^{\mathrm{o}} 2$ reproduce otro personaje masculino y desnudo, pasante hacia la derecha, apoyado también sobre la pierna derecha y con la izquierda flexionada en ángulo recto (fig.3.2). La 
cabeza se representa ladeada y girada hacia el hombro derecho y en el rostro desdibujado no se percibe ningún rasgo anatómico digno de mención. Como en el caso anterior, el personaje despliega los brazos en cruz y el modelado del torso refleja una gran tensión muscular. Porta en la mano izquierda un kantharos de cuerpo gallonado $\mathrm{y}$, en la derecha, una larga vara con una cinta ondeante en su extremo superior y, como remate, un elemento de identidad confusa a causa de su deficiente impresión, aunque pensamos que puede identificarse sin grandes dudas con un thyrsus. Sobre el antebrazo izquierdo apoya una piel de felino con la cabeza y una extremidad delantera colgando hacia delante y la cola y una pata trasera vistas por detrás de la figura, acentuando la sensación de movimiento que imprime el danzante, a quien también identificamos con un sátiro. No resulta fácil asegurar la especie del animal con cuya piel se cubre el personaje. En principio, la abultada crin que se representa sobre la cabeza podría hacer pensar que se trata de un león. Con un concepto figurativo muy semejante encontramos la leonté asociada a la figura de Hércules en una representación pictórica del IV estilo de la Casa dei Postumii, en Pompeya (Coralini, 2001: 86, fig.3). Sin embargo, también exhibe una melena leonina el tigre ${ }^{5}$ sobre el que cabalga Baco asimilado a Eros en un mosaico de la Casa del Fauno (LIMC, III-2: 555, $\mathrm{n}^{\mathrm{o}} 258$ ). Por tanto, esta característica representativa puede no ser un argumento suficiente y definitivo para descartar que la piel que cubre a la figura $\mathrm{n}^{\circ} 2$ fuera en realidad una pardalis, atributo mucho más afín a los miembros del cortejo báquico que la hercúlea leonté ${ }^{6}$.

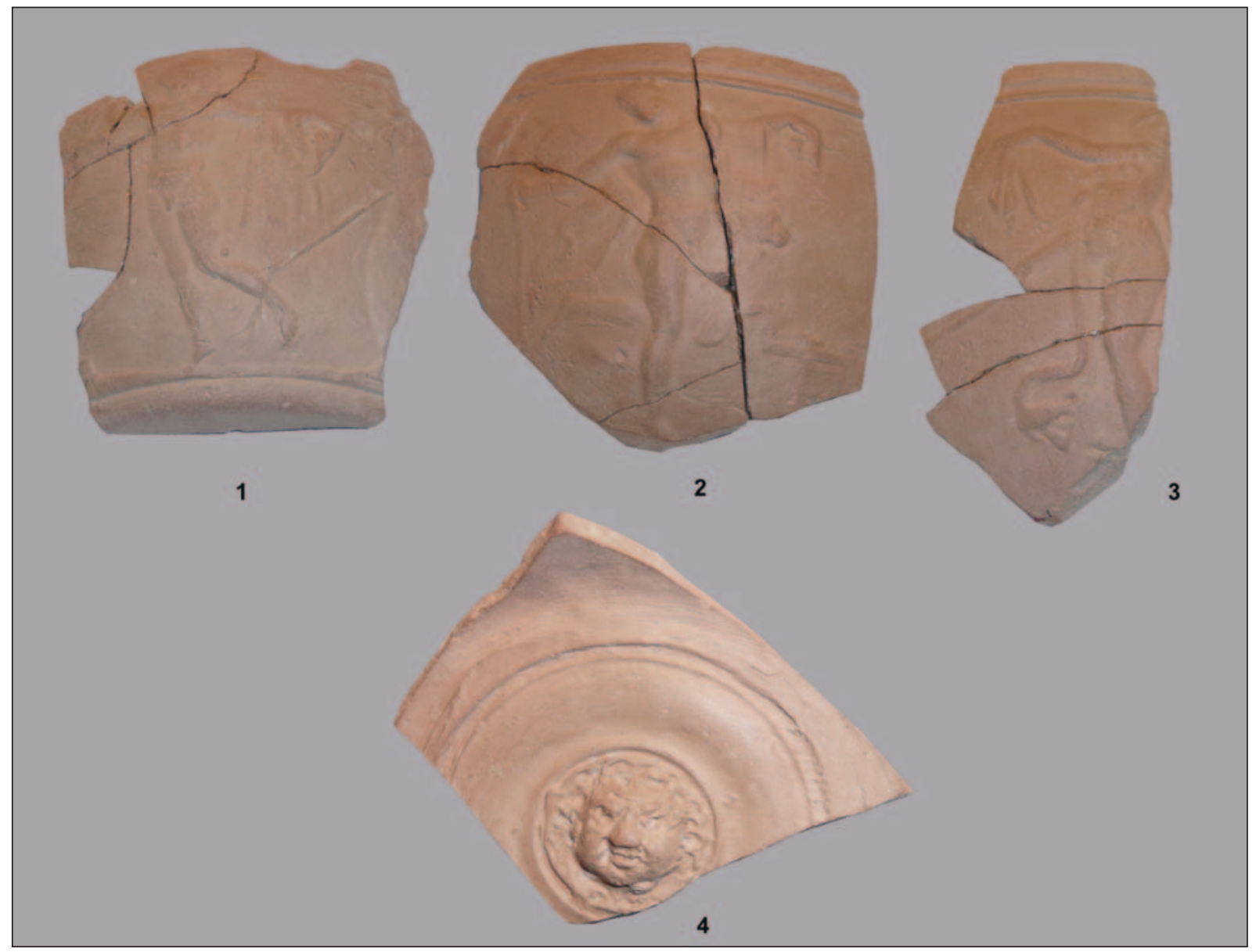

Figura 3. Imagen de los fragmentos conservados

5 El felino en cuestión será descrito en el LIMC (III-2: 559) como un león, pero la piel listada con que se representa parece identificarle con mayor propiedad con un tigre, animal relacionado asimismo con el cortejo báquico y especialmente afecto a las representaciones del paso vic- torioso de Dionisos por la India.

6 En todo caso, la asociación del león con los ritos dionisíacos es antigua y está bien documentada desde el punto de vista iconográfico (LIMC, III-1: 416). 
Entre este personaje y el siguiente -figura $\mathrm{n}^{\mathrm{o}} 3$ se representó en perspectiva un ara de cuerpo prismático, rematada en la zona superior con pulvini (fig.1 y 3.2) La figura $\mathrm{n}^{\circ} 3$ corresponde a una representación femenina desnuda, que discurre hacia la izquierda, dirigiéndose hacia el pequeño altar (fig.3.3). Aunque esta imagen nos ha llegado en estado fragmentario, se aprecia el giro de la cabeza hacia atrás, por encima del hombro izquierdo, mientras sujeta con la mano izquierda el extremo de un vaporoso manto, que parece agitarse al compás de su baile. A juzgar por sus rasgos representativos y el contexto de la figuración, opinamos que se trata de una ménade danzante y no se percibe que en la mano no visible pudiera portar algún objeto musical o cualquier otro atributo afín a estas seguidoras de Dionisos.

Las tres imágenes participan de unos rasgos estilísticos comunes, unificados por un cuidadoso tratamiento de los detalles anatómicos, especialmente perceptible en la musculatura de las figuras masculinas y en la ejecución de las mórbidas curvas del personaje femenino. Este concepto representativo entra de lleno dentro de los parámetros formales del estilo neoático, que impregna numerosas manifestaciones plásticas en el ámbito mediterráneo entre fines del siglo II a.C. y la época augustea (Hauser, 1889; García y Bellido, 1979: 113-114). En sus planteamientos estilísticos y compositivos, el neoaticismo responde a los excesos barroquizantes del Helenismo volviendo la mirada a la Atenas de los tiempos clásicos. La temática de nuestro vaso encuentra también una total afinidad con este encuadre representativo, ya que entre los asuntos que más se prodigan en las decoraciones neoáticas se reflejan diferentes episodios y escenas relacionadas con Dionisos y sus adeptos. Los referentes más claros se hallan en los relieves que decoran diversos tipos de objetos y elementos, como los grandes jarrones de mármol que ornaron las lujosas villas que salpican el territorio itálico en los dos siglos finales de la República y un nutrido conjunto de aras circulares, basas, oscilla y placas relivarias de terracota. No en vano, estos relieves constituyen un conjunto de gran valor ornamental, imbuido de una característica perfección académica y de la innegable elegancia de los originales que sirvieron como prototipos (García y Bellido, 1979: 122).

En este ambiente creativo circularon unos mismos patrones representativos, que se repiten una y otra vez en diferentes combinaciones y con ligeras variantes (Richter, 1925: 202). Así, la figura de perfil del sátiro desnudo y musculado, provisto de pardalis, kantharos y thyrsus, y que ejecuta un paso de danza manteniendo el equilibrio sobre una pierna, mientras flexiona la otra en ángulo recto e inclina extasiado la cabeza hacia atrás, constituyó un tema recurrente en los repertorios neoáticos sobre diferentes soportes (Roscher, 1909-1915: 489). Así, lo hallaremos representado en solitario como decoración de una de las caras de un oscillum galo procedente de Champlay (Lavagne, 2006: 1069, fig.2), o bien formando parte de escenas de thiasos semejantes a la nuestra, como sucede en un ara sepulcral del Museo de los Conservadores (Roma), en una placa de terracota conservada en el British Museum (Richter, 1958: pl. IV, $\mathrm{n}^{\circ} 11$ y 13 ; pl. V, $\left.\mathrm{n}^{\circ} 15\right)$ o en una placa campana (Roscher, 1894-1897: 2277-2278, fig. 14), por sólo citar algunos de los numerosos ejemplos conocidos. Otro referente de excepción para esta figura de sátiro se encuentra en la famosa crátera Borghese, donde el personaje en cuestión forma parte de una escena en la que comparecen varios miembros del cortejo en diferentes actitudes (Bruneau, 1991: 604, fig.6). Trasladado al ámbito del instrumentum domesticum, esta figura se convirtió también en un modelo repetido para la ornamentación de discos de lucernas, como se comprueba en un ejemplar procedente de Córdoba (Rodríguez Neila, 1978-79: 13, $\mathrm{n}^{\circ}$ 7), que puede encuadrarse en una tendencia decorativa en boga sobre el material lichnológico durante el siglo I d.C. (Bernal y García Sanz, 1994: 139) y es especialmente abundante en las fábricas lucernarias itálicas de época de Augusto e inicios de la de Tiberio (Bailey, 1980: Q 1070). El mismo personaje y en similar actitud tuvo también un lugar destacado en el ámbito de la glíptica (Furtwängler, 1900: taf. XLI, n 26, 27 y 29) y en algunas producciones cerámicas con decoración relivaria de época tardohelenística, como los vasos decorados a molde realizados en Pella (Doukellis, 1995: 313).

También la figura femenina de nuestro vaso encuentra sus analogías representativas dentro de lo que se ha dado en denominar el repertorio neoático de las "ménades danzantes" (Touchette, 1995), cuyos prototipos se vinculan con algunas creaciones salidas del cincel de Kallimachos a fines del siglo V a.C. (García y Bellido, 1979: 123). Este muestrario capta el éxtasis dionisíaco de las seguidoras de Dionisos, representándolas en actitud de baile desenfrenado y, las más de las veces, portando atributos bien reconocibles den- 
tro de la atmósfera del thiasos -thyrsus, corona de hiedra-, instrumentos musicales -crótalos, címbalos, tympanon- o elementos relacionados con el sacrificio, como el puñal o el cervatillo (Rolley, 1999: 153-154). El tema de las ménades danzantes hizo fortuna en los talleres neoáticos, ya que se prestaba a una cierta versatilidad representativa que permitía a los escultores cambiar a su gusto el ritmo del baile y el número de ménades en función de la forma y dimensiones del elemento a decorar (Cadario, 2005: 134). Entre las representaciones icónicas de este asunto destacan las lastras marmóreas del Museo del Prado (Madrid), el relieve conservado en la Galeria delle Uffizi (Florencia) (García y Bellido, 1979: 123, fig. 131134 y 135), las magníficas aras del teatro de Itálica (León, 1995: 152-159), una crátera de mármol del Metropolitan Museum of Art de Nueva York (Richter, 1925: pl. VII) o los fragmentos de bases cilíndricas conservados en el Museo Nazionale Romano y los Musei Capitolini, ambos en Roma (Cadario, 2005: 134-137).

Un detalle a tener en cuenta es la desnudez de la ménade que estamos estudiando. En la mayor parte de los casos que acabamos de referir y en muchos otros que engrosan el amplio conjunto de las representaciones menádicas de estilo neoático, lo habitual es que estas mujeres cubran su cuerpo, aunque sea de manera parcial, con chitones transparentes y agiten un manto etéreo al compás de sus movimientos (Daremberg y Saglio, 18751919, III-2: 1487, fig. 4470; García y Bellido, 1979: 123, fig. 135). Sin embargo, el nuestro no es un caso inédito, como ponen de manifiesto algunas otras figuras que se han desprendido parcialmente del chiton, mostrando el cuerpo semidesnudo -como sucede en una de las aras del teatro de Itálica (León, 1995: 159) y en sendas placas del Museo de Nápoles (Roscher, 1894-1897: 2276, fig. 13) y de Chalkis, respectivamente (Grandjouan, Markson y Rotroff, 1989: pl. 25)- o bien se han despojado ya completamente de la túnica y sólo ondean un grácil manto sujeto con las manos o apoyado en los antebrazos (LIMC, VIII2: 795, TH 41; Grandjouan, Markson y Rotroff, 1989: pl. 1, 1). Este último modelo encontró también un cierto eco en la pintura mural, como se comprueba a través de diversos ejemplos (Reinach, 1970: 130, 1; 132, 6; 133, 2 y 3).

Una vez comentadas las figuras de manera individual, habría que considerar su relación semántica en el marco de este friso decorativo. En este sentido, estimamos que no se trata de meras figuras yuxtapuestas, dentro del concepto de disiecta membra que se hace explícito en algunas decoraciones de vasos a las que nos referiremos después con mayor detalle (Courby, 1913: 425). En el vaso sisaponense los personajes parecen formar parte de una acción narrativa única centrada en el ara, elemento en torno al cual los sátiros y la ménade ejecutan sus pasos de baile en pleno éxtasis dionisíaco. Bien es verdad que el ara aparece también en otras decoraciones de temática menos unitaria, como sucede en la crátera firmada por Sosibios (González Serrano, 2004: fig.5); pero en este caso los personajes seleccionados entre el repertorio de temática dionisíaca se acompañan de otros prototipos, como el pyrrhichista, y de divinidades como Apolo, Hermes y Artemis, sin que el conjunto forme parte de un episodio mitológico concreto o de una escena con vocación narrativa.

Un último asunto a abordar dentro del comentario de los aspectos decorativos del vaso que analizamos es el relativo al relieve aplicado que figura en el fondo interno. Se trata de una cabeza de Gorgona, que se encuentra enmarcada por un círculo inciso, inscrito a su vez en otro más amplio que conserva indicios de decoración burilada (fig.3.4). La cabeza se representa de frente, con un rostro de dilatadas facciones, con ceño fruncido y pómulos prominentes, nariz ancha, poderosa barbilla y boca carnosa por la que no asoman ni los colmillos ni la lengua. Alrededor del rostro, la orla de cabellos o serpientes ha sido desdibujada por el instrumento empleado para la fijación del relieve, por lo que apenas se pueden reconocer dos alas de coronamiento sobre la frente y el nudo de serpientes bajo el mentón. Por último, los ojos redondos transmiten el carácter "terrible" del personaje, con una hierática pupila marcada por la incisión de un punzón de sección circular. Esta representación se encuentra a caballo entre las figuras terroríficas del mundo griego y etrusco (LIMC, IV-2: 190-192; Mack, 2002) y la efigie serena y contenida de la Medusa Rondanini y sus réplicas (LIMC, IV-1: 347; IV-2: 196, nº 25 y 27; Buschor, 1958; Belson, 1980). Como sucede en numerosas figuraciones de época romana (García Merino, 1990: 245), se elige una versión de Gorgona con el rostro de frente, adecuado a un marco de forma circular, y con el semblante contraído en una mueca de contenida fiereza, encriptada en un rictus que contrae e infla los pómulos y en una mirada fija y profunda, destinada a petrificar a quien osara mirarla. Este prototipo de gor- 
goneion se encuentra ya desarrollado durante el Helenismo temprano y está llamado a perdurar largo tiempo en las producciones imperiales (Gilotta, 1985: 34).

Las representaciones de la cabeza de Gorgona poseen una trayectoria iconográfica enraizada en las fases iniciales de la cultura material griega (Daremberg y Saglio, 1875-1919, II-2: 16191621; Howe, 1954), que se mantiene vigente en tiempos helenísticos y romanos, donde será representada sobre soportes y materiales muy diversos y con una significación estrechamente abrazada al concepto de apotropaion, adaptado al ámbito particular de cada una de sus esferas representativas (Giuliano, 1960: 882-885; Floren, 1977). Su presencia en el instrumentum domesticum durante el tardío Helenismo y la primera etapa imperial se materializa en las vajillas, tanto metálicas como cerámicas (Labrousse, 1954: 307, fig. 5; Sanmartí y Gusi, 1975: 167-168; Thompson, 1934: 352355; Casas, Merino y Soler, 1993: 139, fig. 8, ${ }^{\circ}$ 33; Mínguez, 1995: 163, fig. 5; Pozo, 2005: 55, lám. 16), en piezas excepcionales talladas en piedras semipreciosas (Furtwängler, 1900: taf. LIV; La Rocca, 1984) y también en lucernas (Walters, 1914: 170-171, no 1128 y 1129); Ponsich, 1963: 110 , pl. III, $\mathrm{n}^{\circ} 38$, entre otros muchos ejemplos).

\section{El CONTEXTO PRODUCTIVo Y EL MARCo CRONOLÓGICO}

A juzgar por su técnica y estilo decorativos, un primer encuadre para el vaso que estamos analizando podría enfocar la búsqueda de su contexto productivo dentro de la koiné mediterránea de las producciones helenísticas con relieves ${ }^{7}$. Estas fábricas cerámicas, denominadas durante largo tiempo "megarenses" y cuyo origen se localiza en el Mediterráneo oriental, se especializaron en la realización de boles hemisféricos con decoración a molde. Tal y como refiere M. Py (1993 a: 132), algunos autores han defendido que el foco inicial de la producción surge en Atenas durante la segunda mitad del siglo III a.C. y más concretamente entre los años 240-220 a.C. (Rotroff, 1982 a: 9-13). Recientemente, estas fechas han sido algo más aquilatadas en virtud de la precisión que ofrecen las ánforas rodias con las que normalmente suelen estar relacionados estos materiales, por lo que puede defenderse un arranque de la producción datable a inicios del último cuarto del siglo III a.C. y de manera verosímil a partir del 224-3 a.C. (Rotroff, 2006: 373). Desde comienzos del siglo II a.C., este concepto alfarero se difunde en la Grecia continental, Chipre y el área jónica (Py, 1993 a: 132) y durante la primera mitad de la citada centuria alcanzará también Italia (Puppo, 1995: 29). Este éxito productor explica en parte su importante difusión, lo que la convierte en una de las producciones cerámicas más características en los contextos helenísticos, prácticamente equiparable a la cerámica de barniz negro itálico, tal y como han propugnado algunos investigadores (Siebert, 1980: 56).

La historia de la investigación sobre estas producciones en el ámbito helénico arranca del segundo cuarto del siglo pasado y ha sido compendiada en sus líneas fundamentales por S. Rotroff (2006: 358-359), por lo que no consideramos necesario extendernos en este asunto. A lo largo de estos casi cien años de estudios, se han ido individualizando grupos regionales y talleres que permiten localizar su producción en Atenas, Beocia, el Peloponeso, Jonia, Pérgamo, Delos, Macedonia y Chipre (Courby, 1922; Schwabacher, 1941; Edwards, 1956; Schafer, 1968; Laumonier, 1973 y 1977; Siebert, 1980; Edwards, 1981; Rotroff, 1982 a; Akamatis, 1993, entre otros). Asimismo, la implantación de talleres en Italia central y Sicilia de lo que se ha venido denominando hasta fechas recientes "producciones italo-megarenses" (Marabini,
7 Esta opinión sustenta también M. Beltrán Lloris, quien ha tenido la amabilidad de examinar directamente la pieza y a quien agradecemos encarecidamente sus comentarios sobre la misma.

8 Este calificativo toponímico le fue impuesto por O. Benndorff (1877: 118) al considerar que su producción estaba vinculada estrechamente con el núcleo homónimo. A pesar de que desde los años 20 del siglo pasado la mul- tiplicidad de lugares productores es una evidencia muy bien contrastada, la denominación "megarense" o "megárica" caló profundamente en la bibliografía arqueológica, en la que se ha mantenido hasta fechas recientes, especialmente en el ámbito italiano (Falco, 2000; Puppo, 2001, Mosca, 2001), donde se justifica como un intento de evitar la larga perífrasis de su denominación más correcta (Puppo, 1995: 17). 
1980; Puppo, 1995), ha sido también objeto de investigación específica desde fechas incluso anteriores a las de las producciones del Mediterráneo oriental, ya que las series firmadas empezaron a darse a conocer a fines del siglo XIX (Puppo, 1995: 21-30; Leotta, 2005: 51).

Sin embargo, a la hora de relacionar el vaso sisaponense con una producción concreta de cerámica helenística con relieves se nos plantean varias dudas. La primera es de índole tecnológico y tiene que ver con el acabado de nuestra pieza, que está desprovista de barniz. Este rasgo de manera casi inmediata dirige nuestra búsqueda al ámbito centroitálico, dado que la ausencia de barniz fue frecuente en la mayor parte de las series fabricadas en este ámbito geográfico, como demuestran las producciones firmadas por Popilius, Quintius y Herakleides o las realizadas en Tivoli y en Cosa (Marabini, 1980; Puppo, 1995: 44-74; 81-88; Puppo, 2001: 247-250) ${ }^{9}$. Por el contrario, la presencia de barniz constituye una característica bastante reiterativa en sus contextos productivos del Mediterráneo oriental y Grecia continental. En efecto, aunque se trata de producciones muy dispares, que albergan series de gran calidad junto a otras mucho más toscas ${ }^{10}$ (Siebert, 1980: 56), lo habitual es que estos boles exhiban un revestimiento cuya tonalidad oscila entre el rojizo y el castaño oscuro o negruzco y su calidad fluctúe entre productos muy brillantes, de apariencia casi metálica, y otros muy mates y poco adherentes.

El problema surge a la hora de correlacionar este parámetro técnico con la configuración formal de nuestra pieza, ya que su perfil se aproxima más a las series del Mediterráneo oriental que a las itálicas. En efecto, el vaso presenta una conformación del cuerpo y el borde que encuentra sus mayores analogías en el llamado "perfil délico" (Courby, 1922: 279-280; Siebert, 1980: 83, fig. 8), que corresponde al tipo B-H-R-8 de Py (1993

9 Sin embargo, estos parámetros técnicos contrastan con los del área meridional que, por su estrecha relación con los ambientes griegos, muy rara vez aparecen sin barniz (Leotta, 2005: 51).

$10 \mathrm{El}$ autor que venimos citando afirma que incluso un mismo taller podía estar realizando materiales de diferentes calida- a: 133). Se trata de una copa de cuerpo hemisférico, ligeramente achatado, con el borde vertical y el labio redondeado o suavemente almendrado y el fondo plano. No obstante, hacemos notar que el vaso sisaponense muestra algunos rasgos distintivos que introduce discrepancias con el perfil que acabamos de describir, como una relación diferente entre el ancho y la altura, que se resuelve en este caso a favor de la primera.

Una segunda cuestión problemática se refiere al concepto y temática ornamental que presenta la pieza. Tanto las producciones orientales como las itálicas ofrecen una sintaxis decorativa que estructura el vaso en varios frisos con decoración continua situados bajo el borde y un gran tema, generalmente vegetal, que parte del fondo y abraza buena parte del cuerpo del vaso. En el ámbito itálico resultan bastantes raras las decoraciones figuradas (Leotta, 2005: 51), pero no están del todo ausentes, como evidencia el espléndido vaso firmado por Popilius que reproduce de manera espectacular una batalla entre griegos y bárbaros, quizá el famoso enfrentamiento entre Alejandro y Darío, o una copa procedente de Gela con una franja decorada con una secuencia de erotes a caballo (Puppo, 1995: 50 y 108). Algo semejante sucede en el extremo oriental del Mediterráneo y el continente griego, donde, entre las ricas series con decoración vegetalizada o geométrica, destacan algunos ejemplares antiguos con vocación narrativa, como los conocidos en la bibliografía de esta producción como "cuencos homéricos" (Weinberg, 1949, pl. 15, no 8-9; Akamatis, 1996). Sin embargo, como acertadamente sintetiza G. Siebert (2004: 23), la historia de los boles helenísticos con decoración en relieve estará marcada por el conflicto entre una estética narrativa y una estética decorativa, de manera que en las fases más antiguas predominará el primer concepto para ir cediendo paso a los planteamientos propios de una cierta banalización representativa, más acorde con la estandarización de la producción en la fase álgida de su experiencia comercial.

des en función del grado de uso de los moldes, de la cantidad de vasos impuesta por la demanda o por la intervención de manos más o menos hábiles en las diferentes fases del proceso productivo (Siebert, 1980: 68). 
Bastante más cercanas a nuestro patrón decorativo son las series producidas en Pella, donde algunos vasos exhiben su decoración figurada en un único registro y se encuentran ejemplares con temática sensiblemente similar a la copa de Sisapo (Akamatis, 1993; Doukelis, 1995: 313). En el caso citado, vemos una secuencia de personajes relacionados con el cortejo de Dionisos, cuyos punzones remiten también claramente a los repertorios neoáticos ${ }^{11}$, aunque en este caso parece tratarse de una serie de figuras yuxtapuestas, sin voluntad de representar una escena unitaria. Asimismo, esta producción macedonia asocia el gorgoneion a la decoración del vaso, aunque aquí aparecerá decorando el fondo externo y no el interior. La cabeza de Gorgona como protagonista de la ornamentación del fondo externo aparece nuevamente en otros ejemplares procedentes del Ágora de Atenas (Thompson, 1934: 353, fig. 36b; 354, fig. 37; 355, fig. 39; 356, fig.40) y de otros centros productivos orientales (Baur, 1941: 233).

En síntesis, en el vaso que estamos analizando convergerían características técnicas propias de los ambientes centroitálicos con aspectos formales y decorativos radicados en el Oriente mediterráneo. Quizás este fenómeno podría explicarse en el contexto de una fabricación centroitálica, relacionada con un taller aún poco conocido, influido por los materiales de importación que llegan a la península itálica desde fechas tempranas por la vía del comercio con los ambientes grecoorientales $^{12}$. En tal caso, habría que pensar en una producción poco masiva y con una limitada capacidad de difusión, dada la singularidad de este vaso en los contextos hispanos por el momento ${ }^{13}$.

Sin perjuicio del encuadre productivo que acabamos de pergeñar y basándonos en la falta de referentes idénticos a nuestra pieza, no consideramos baladí comentar las relaciones existentes con otras fábricas cerámicas también inscritas en la

11 La relación entre el estilo neoático y los vasos helenísticos con decoración en relieve fue enfatizada desde momentos tempranos en la secuencia de estudios sobre estas producciones (Richter, 1958: 14).

12 Esta misma opinión nos ha trasmitido M. Beltrán. Los contextos comerciales que arroparían estos fenómenos se inscriben en las redes comerciales que unieron los dos extremos del Mediterráneo y en las que participaron los negotia- koiné helenística mediterránea. Sería el caso de las llamadas cerámicas pergamenas con relieves aplicados. Estos materiales, originarios del lugar que les da nombre (Courby, 1913: 436), se fabricarían entre el último cuarto del siglo II a.C. y el 75-60 a.C., estando en todo caso ya ausentes de los contextos estratigráficos de inicios de época augustea (Bruneau, 1991: 609). El marco de comparación que establecemos con estos productos se orienta exclusivamente hacia el concepto y estilo decorativos, ya que desde los puntos de vista tecnológico y morfológico existen netas diferencias entre el vaso sisaponense y las producciones pergamenas. La primera distinción se refiere nuevamente al acabado de estas cerámicas, que se caracterizan por un recubrimiento de brillante color rojo coral, similar al de la terra sigillata itálica (Courby, 1913: 418; Bruneau, 1991: 600). Tampoco el repertorio formal de las cerámicas pergamenas muestra afinidad con el perfil del vaso de La Bienvenida, ya que entre los productos salidos de estos talleres no hemos hallado ningún morfotipo análogo.

El puente de unión entre estos productos y la pieza que estudiamos viene dado, por un lado, por el estilo de las representaciones figuradas y, por otro, por el empleo de la técnica del relieve, aplicado en nuestro caso a la decoración del fondo interno. En cuanto al primer asunto, uno de los ámbitos temáticos que encuadra las decoraciones figuradas de las cerámicas pergamenas con relieves aplicados será precisamente el de los personajes relacionados con el thiasos dionisíaco, extraídos también en su mayor parte de los repertorios figurativos neoáticos (Bruneau, 1991: 604-605). Esta decoración se realizó mediante la aplicación sobre el vaso torneado, de motivos previamente impresos sobre una placa de arcilla (Courby, 1913: 419). Estos motivos trabajados individualmente podían ser fácilmente intercambiables en

tores itálicos, con bases en puntos estratégicos para esta actividad como Delos o Éfeso (Falco, 2000: 385).

13 No sucede lo mismo con otras producciones de cerámicas de relieves más universales, que se documentan en la península Ibérica en diversos lugares que gravitan en torno a Cartagena y Baleares, así como en la costa alicantina y murciana y, con carácter más puntual, en Cataluña, el valle del Ebro y Andalucía (Cabrera, 2004: 8). 
composiciones diversas, aunque parece que en la práctica se aplicaron sin tener en cuenta las relaciones temáticas de figuras y personajes (Bruneau, 1991: 598-599). Precisamente, esta técnica la constatamos en nuestro ejemplar, si bien su posición en el fondo interno resulta inédita en el campo de los materiales pergamenos que estamos ahora tratando. Sin embargo, esta modalidad ornamental sí se documenta en los ambientes itálicos de la segunda mitad del siglo III a.C. y primeros años de la centuria siguiente, como los relacionados con la producción de las cerámicas de tipo caleno (Morel, 1980: 95) y otras producciones de barniz negro suritálico (Abad, 1983: 188-189). En efecto, estas categorías cerámicas albergan páteras con el medallón central decorado con cabezas de divinidades o de otros personajes mitológicos, entre ellos la Gorgona (Nordström, 1961: 54, fig.15; Gusi, 1974: 120, fig.1; Py, 1993 b: 145). Aunque es obvio que nuestra pieza no se inscribe técnicamente en estas producciones, no deja de ser interesante la relación que vuelve a manifestar con materiales cerámicos inscritos en los ambientes helenísticos itálicos.

A la vista de estos importantes problemas de atribución, es menester exponer los resultados de los análisis arqueométricos realizados al vaso de La Bienvenida y que han consistido en la descripción de lámina delgada por microscopía óptica de polarización y en el estudio de la composición mineralógica por Difracción de Rayos $\mathrm{X}^{14}$. El estudio de la textura y mineralogía de lámina delgada por microscopía óptica de polarización $^{15}$ muestra un conglomerado artificial consistente en un cemento homogéneo de coloración castaña homogénea en la parte central y en los bordes más clara y con granulometría más fina (fig.4.1). En la pasta se reconocen escasos desgrasantes de mayor tamaño, constituidos por cristales de feldespatos aristados, óxidos de hierro amorfos, cuarzos policristalinos con extinción ondulante y fragmentos de rocas metamórficas tipo gneis. En tamaño

\footnotetext{
${ }^{14}$ Estos análisis han sido realizados por la Dra. Rosario García Giménez (Prof ${ }^{a}$. del área de Cristalografía y Mineralogía, del Dpto. de Geología y Geoquímica de la UAM), a quien agradecemos su constante e inestimable
}

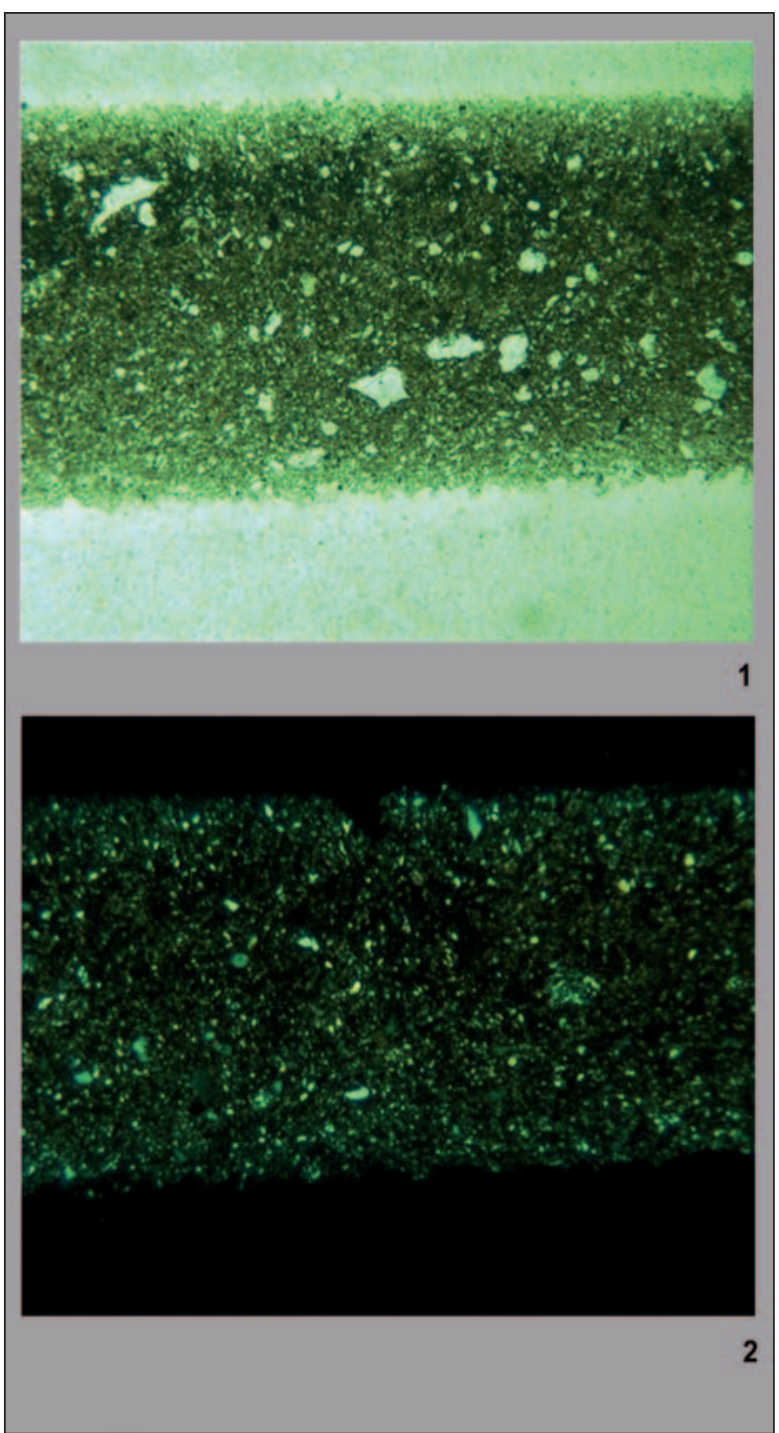

Figura 4.1. Lámina delgada observada con luz blanca (X64). 2. Lámina delgada observada con luz polarizada (X64) (R. García Giménez).

menor se identifican, además de los mismos cristales descritos antes cristales de biotita, flogopita y moscovita, junto a hornblenda, hematites y minerales opacos (fig.4.2).

Desde el punto de vista de la manufactura se reconocen algunos huecos fusiformes y oquedades redondeadas, posiblemente debidas a procesos de transformaciones de fases en las que se desprenden gases, creando burbujas (fig.5.1). 


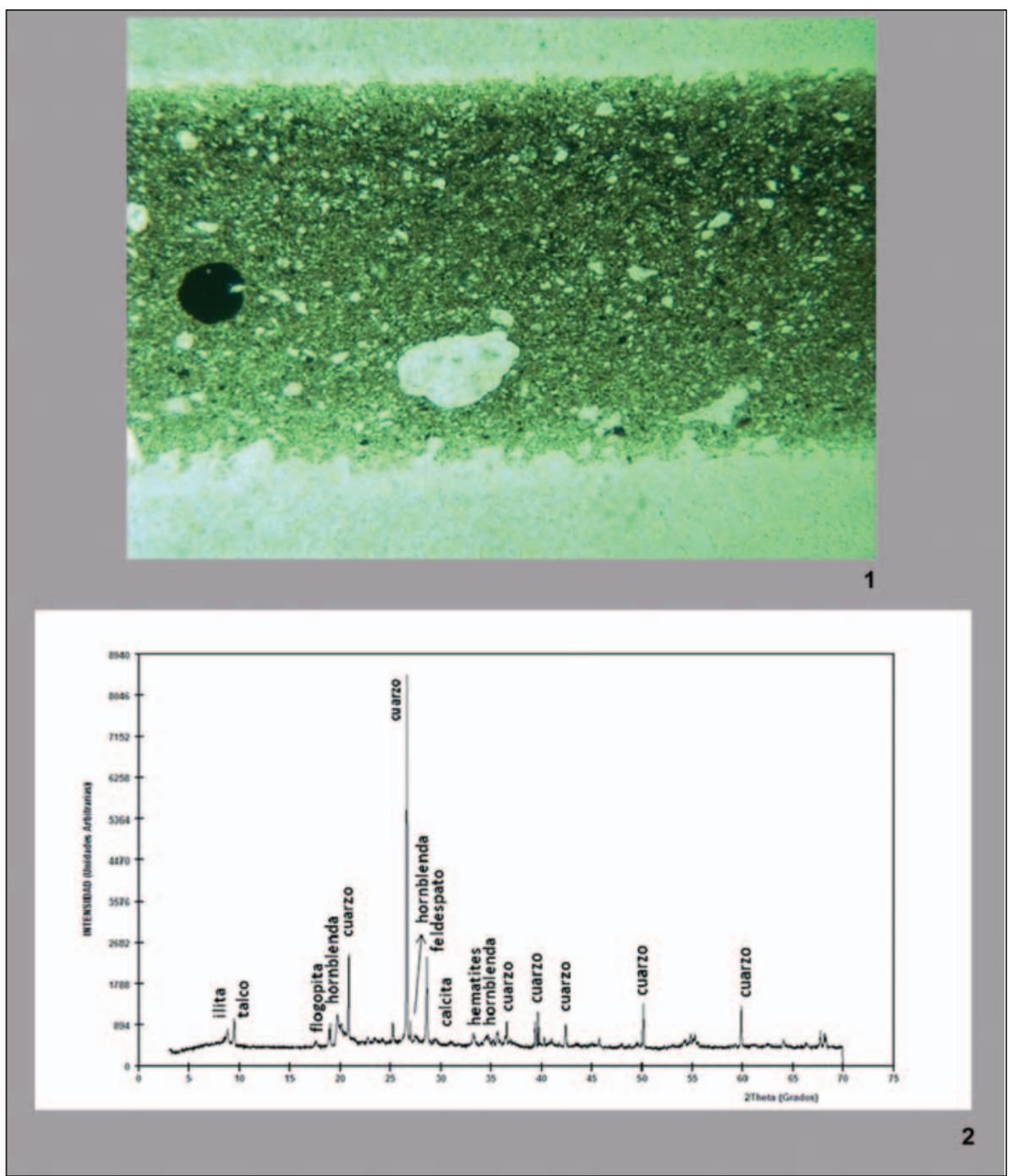

Figura 5.1. Lámina delgada observada con luz blanca (X64), con identificación de huecos fusiformes. 2. Espectro de difracción de Rayos X (R. García Giménez).

En cuanto al estudio de la composición mineralógica por Difracción de Rayos $\mathrm{X}^{16}$, en el estudio de los picos de difracción de la muestra en polvo se identifican las siguientes especies minerales: illita $(10,06 \AA)$, talco $(9,37 \AA)$, flogopita $(5,05 \AA)$, hornblenda $(4,51 \AA$ y $2,58 \AA)$, cuarzo $(4,25 \AA, 3,34 \AA, 2,46 \AA, 2,24 \AA$ y $1,98 \AA)$, feldespatos $(3,23 \AA$ y $3,11 \AA)$, calcita $(3,03 \AA)$, hematites

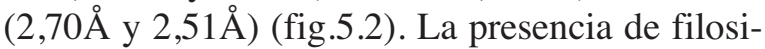
licatos de illita confirma que la temperatura de cocción no habría superado el umbral de los $850^{\circ} \mathrm{C}-1000^{\circ} \mathrm{C}$. Pero, en cambio, estos resultados no han arrojado datos sobre la presencia de ele-

16 Los difractogramas se han realizado en un difractómetro SIEMENS D-5000. Los espectros de polvo desorientado se han registrado desde 3 a 65 grados con una velocidad de barrido de 2 grados por minuto. El tubo generador de rayos $\mathrm{X}$ utiliza como cátodo un filamento de wolframio y como mentos traza que nos orienten sobre el origen de la arcilla empleada en su confección.

Por tanto, hemos de concluir que esta aproximación al contexto productivo de la pieza es un tema aún totalmente abierto y susceptible de ser más preciso en la medida en que pudieran aparecer nuevos ejemplares de características similares. En principio, como venimos reiteradamente apuntando, el estilo representativo y la técnica de la decoración parecen perfilar un encuadre centrado en tiempos tardohelenísticos, prolongables a la época augustea, pero no debe olvidarse que la rea-

ánodo una placa de cobre $\left(\mathrm{CuK}_{\text {? }}\right)$. La intensidad de corriente $\mathrm{y}$ voltaje aplicados al tubo generador de rayos $\mathrm{X}$ ha sido de $30 \mathrm{~mA}$ y $40 \mathrm{Kv}$ y las rendijas de divergencia y recepción de 1 y 0,18 grados, respectivamente. 
lización de cerámicas helenísticas con decoración a molde encontró continuidad en producciones tan universales como la terra sigillata o en otras algo más restringidas como las cerámicas corintias con relieves, ambas con definitorios acabados barnizados que, una vez más, contribuyen a marcar distancias con nuestro vaso ${ }^{17}$.

Lo que sí tuvo en común con la mayor parte de las producciones que hemos ido comentando es una indudable relación con prototipos metálicos, que en nuestro caso afecta tanto a la decoración de la pared exterior a molde como al relieve aplicado en el fondo interno. De hecho, la imitación de modelos toréuticos es una evidencia innegable en el caso de las producciones de tipo caleno (Richter, 1959), en las cerámicas helenísticas con relieves de tipo "megarense" (Siebert, 1980: 56) o en las pergamenas con relieves aplicados (Courby, 1913: 425). Incluso en algunos casos, se ha llegado a hablar del empleo de la técnica del sobremolde obtenido directamente de piezas realizadas en metales preciosos (Courby, 1913: 430; Bruneau, 1991: 605). Estos fenómenos fueron comunes desde la época helenística, en un intento de emular la riqueza de la vajilla de oro y plata por parte de productos de un valor muy inferior (Rotroff, 1982 b: 330) ${ }^{18}$ y se mantienen en tiempos romanos, tal y como se infiere del hallazgo de impresiones sobre arcilla obtenidas de originales metálicos griegos (Richter, 1958: 14). Esta última afirmación abriría, a nuestro juicio, otra posible vía de trabajo en la valoración del vaso de La Bienvenida, ya que no nos parece descabellado pensar en el uso de un sobremolde obtenido a partir de un original metálico, a pesar de las opiniones que reivindican un papel más creativo para los ceramistas, desvinculado de la copia fiel de los trabajos toréuticos (Siebert, 2004: 21).

17 Los conocidos como "boles corintios con relieves" identifican una producción que gravita en torno a la citada ciudad griega (Spitzer, 1942), entre la segunda mitad del siglo II y fines del siglo III d.C., y que se difundió hacia el Occidente del Mediterráneo, alcanzando diversos puntos de la geografía itálica (Malfitana, 1999) y de la fachada oriental hispana (Granados, 1977; Quevedo, 2009: 219). El repertorio más característico está representado por unos boles de forma cilíndrica con pie bajo y decoración a molde concentrada en un único friso, delimitado en ambos extremos por hileras de círculos o incisiones (Spitzer, 1942: 163-165). En todo caso, el estilo decorativo de estos materiales, calificado de
Otra incógnita que se cierne sobre el ejemplar que estamos estudiando es la relativa a su encuadre temporal. En las líneas precedentes hemos apuntado el amplio contexto cronológico en el que suelen encontrarse los materiales con los que encuentra más afinidad, presentes en numerosos ámbitos entre el último cuarto del siglo III a.C. y la época augustea en algunos casos. Desafortunadamente, el vaso dionisíaco sisaponense apareció fuera de su contexto original. Sus fragmentos se hallaron en la domus de las Columnas Rojas, en un estrato compuesto por material latericio (eminentemente tégulas e ímbrices) (UE 93), muy probablemente relacionado con el desplome de la cubierta del pasillo del peristilo. Esta unidad se sobrepone a una serie de acumulaciones de fragmentos de pintura decorativa, datados en momentos avanzados del siglo II d.C. (Hevia, Corral y Sierra, 2007) y que conforman una superficie "solada", en uso durante las ocupaciones puntuales de que fue objeto la vivienda antes de su colapso definitivo. Es posible que la pieza estuviera incluida entre los elementos amortizados por los nuevos ocupantes para la formación de superficies de uso o bien formara parte de las acumulaciones de desechos de distintas zonas de la vivienda tras su primer abandono, como se ha constatado en otros puntos de la misma. Pero no cabe la menor duda de que se encontraba fuera de su contexto cronológico y funcional de uso. Su relación con los momentos de uso inicial de la vivienda no sería inverosímil, dado que el proyecto arquitectónico original puede datarse con criterios estratigráficos y constructivos a inicios del siglo I d.C. y, como hemos visto, en el encuadre estilístico de la decoración del vaso, la corriente neoática encontró un importante cauce representativo sobre diferentes soportes en época augustea

"impresionista" por la autora que venimos citando (Spitzer, 1942: 165), no muestra analogías representativas con el vaso sisaponense.

18 No obstante, estos materiales que están imitando en un material mucho más barato las onerosas vajillas metálicas se han considerado a su vez productos "de lujo" (Cabrera, 2004) en el contexto de las importaciones cerámicas de la península Ibérica entre los siglos III y I a.C. Otros autores, por el contrario destacan el carácter utilitario de estas cerámicas, que surgieron para imitar la verdadera vajilla de lujo y que presentan unos parámetros de calidad extraordinariamente variables (1980: 55). 


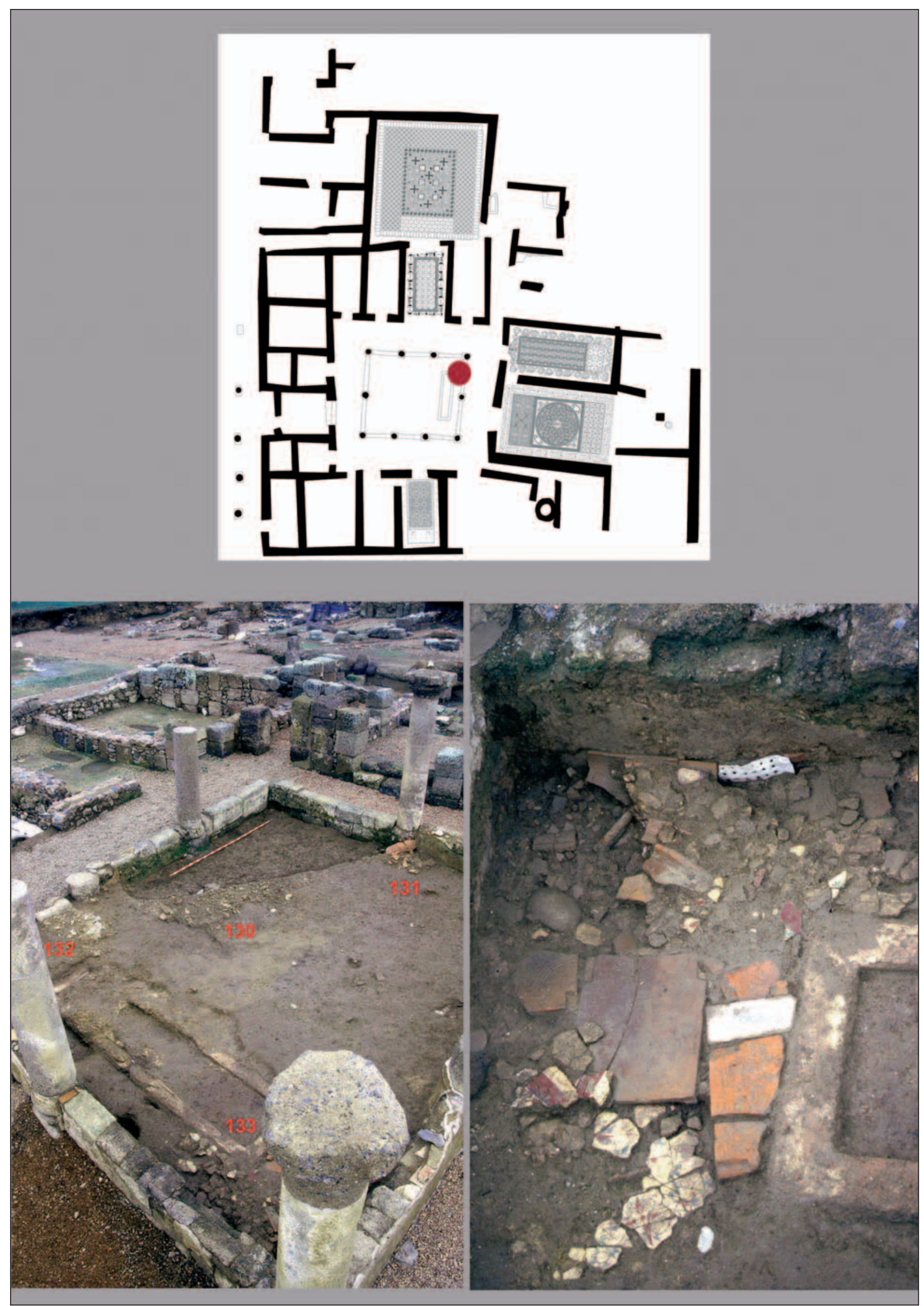

Figura 6. Lugar y contexto de aparición de la pieza. 
(Paillier, 1982: 769; León, 1995: 50-52; Cadario, 2005: 136; Lavagne, 2006: 1086).

Por lo que respecta a la posible funcionalidad del vaso, tanto la temática dionisíaca de la pared exterior como el gorgoneion del fondo interno ${ }^{19}$ pueden hacer pensar que se trata de un recipiente relacionado con el consumo de vino. De hecho, los cuencos de relieves helenísticos se han vinculado con los caldos itálicos $\mathrm{y}$, de manera más específica, con el vino griego, como muestra su relación con las ánforas rodias en los contextos mediterráneos (Pérez Ballester, 1994). En el ámbito de Carthago Nova, este consumo se ha relacionado con los comerciantes itálicos o de origen oriental establecidos en la ciudad entre fines del siglo II y mediados del I a.C. En nuestro yacimiento, la presencia de este material puede ponerse en relación con la instalación de gentes itálicas vinculadas a la societas que gestionó la explotación de las minas sisaponenses. No en vano, los contextos arqueológicos de la ciudad muestran una especial pujanza en tiempos tardorrepublicanos (Arévalo y Zarzalejos, 1995: 164) y augusteos (Fernández Ochoa et alii, 1994: 154-155).

Sin embargo, una posible objeción a su empleo como copa relacionada con un consumo "continuado" de vino vendría dada por la ausencia de barniz y la contrastada porosidad de sus superficies. En este sentido, parece interesante hacer constar el hallazgo de vasos "italo-megarenses" en contextos cultuales y funerarios, donde se considera que pudieron emplearse en actos rituales (Puppo, 1995: 20), función ésta que también se hace extensiva a los cuencos con medallón en relieve (Cabrera, 2004: 10). A juzgar por el lugar donde ha sido recuperado el vaso sisaponense, en la zona descubierta del peristilo, tendría cierta lógica pensar que quizás formó parte del ajuar relacionado con los cultos domésticos, que en este modelo de vivienda se sustanciaban muy frecuentemente en el peristilo (Thébert, 1991: 353).
Las numerosas campañas de excavaciones realizadas en La Bienvenida han ido aportando información histórica de primera mano sobre la larga trayectoria de la antigua Sisapo desde la etapa tartésica hasta el fin de la romanidad. Más allá de las reparos metodológicos que se le puedan poner al estudio de una pieza concreta -la siempre denostada "arqueología objetual"- creemos que a través del estudio detallado de este excepcional cuenco sisaponense se vuelve a poner de relieve la importancia y significación del yacimiento y el papel que jugó Sisapo en los momentos cruciales entre el periodo republicano y la implantación del dominio imperial en los ámbitos mineros de Sierra Morena.

\section{A modo de Elogium (por Carmen Fernández OCHOA)}

Antes de finalizar esta aportación y con el seguro beneplácito de mi compañera de firma, quiero destacar con brevedad pero de manera decidida e inequívoca, la labor de Manuel Bendala en sus largos años de permanencia en nuestra Universidad. Cuando llegó a la Universidad Autónoma de Madrid en 1976, el conjunto de las actividades del Departamento presentaba un perfil de recorrido limitado en el campo de la investigación de la Arqueología Hispanorromana. Su inmediata disponibilidad, su presencia siempre amable y generosa así como sus ganas de trabajar abrieron un camino nuevo y relevante para la mayoría de los que estábamos interesados en esa línea de trabajo. Si se me permite la expresión, bajo el paraguas del profesor M. Bendala se fueron aglutinando ayudantes, jóvenes investigadores y becarios que hoy en día, dispersos en distintos centros y museos, conforman un importante activo en la arqueología española, con notable capacidad de estudio y proyección nacional e internacional en el tratamiento de los fenómenos histórico-arqueológicos desde el periodo tardoibérico hasta el definitivo asentamiento de la romanidad.
19 Recordamos en este sentido, la vieja relación del gorgoneion con los vasos destinados al consumo de vino en el symposion griego, tal y como muestra la nutrida serie de cílicas con la cabeza de la Gorgona en el fondo interno o en la pared exterior, flanqueada por dos grandes ojos (Mack, 2002: 576; fig. 2,3 y 13). 
Con independencia de su reconocido magisterio, algunos colegas hemos tenido la suerte de contar siempre con su ayuda, sus consejos y su cercanía vital. Tras más de treinta años de trabajo en el mismo Departamento, creo haber compartido con Bendala muchas vivencias en común, siempre con el mismo objetivo: la búsqueda de una docencia de calidad, la inquietud continuada por la investigación y una solidaridad inquebrantable cuando arreciaban los problemas que, en mi caso y dada mi dedicación a la arqueología urbana y patrimonial, llegaron a convertirse en auténticas pesadillas. Pero desde la perspectiva actual, lo que más valoro de estos años vividos con Manuel Bendala es que siempre haya querido contarme entre sus amigos. A fin de cuentas y, a pesar de las muchas cosas aprendidas y compartidas, su mejor legado siempre será su indiscutible calidad humana. Y ella es la que ha inspirado este modesto homenaje que Mar Zarzalejos y yo hemos querido ofrecerle.

\section{Bibliografía}

ABAD CASAL, L. (1983): "Un conjunto de materiales de la Serreta de Alcoy (Alicante)", Lucentum, 2, 173-197.

AKAMATIS, I. M. (1993): Clay vase moulds from Pella. A contribution to the study of Hellenistic Pottery, Athens.

AKAMATIS, I. M. (1996): "Spolium homericum pellense", Tekmêria, 2, 1-7.

ARÉVALO, A. Y ZARZALEJOS, M. (1995): "Apuntes para las claves interpretativas de la Sisapo republicana: testimonios materiales", Actas del XXIII Congreso Nacional de Arqueología, II, Elche, 161-170.

BAILEY, D. M. (1980): Catalogue of the Lamps in the British Museum, II: Roman Lamps made in Italy, London.

BAUR, P. V. C. (1941): "Megarian Bowls in the Rebecca Darlington Stoddard Collection of Greek and Italian Vases in Yale University", American Journal of Archaeology, 45 (2), 229-248.

BELSON, J. D. (1980): “The Medusa Rondanini: A New Look", American Journal of Archaeology, 84 (3), 373-378.
BENDORFF, O. (1883): Griechische und sizilianische Vasenbilder III, Leipzig.

BERNAL CASASOLA, D. Y GARCÍA SANZ, O. (1994): "Iconografía dionisíaca en lucernas de la Hispania romana", Cuadernos de Prehistoria y Arqueología de la Universidad Autónoma de Madrid, 21, 117-158.

BRUNEAU, Ph. (1991): "La céramique pergamienne à reliefs appliqués de Délos", Bulletin de Correspondance Hellénique, 115 (2), 597-666.

BUSCHOR, E. (1958): Medusa Rondanini, München.

DAREMBERG, Ch. Y SAGLIO, E. (1875-1919): Dictionnaire des Antiquités grecques et romaines d'aprés les textes et les monuments, Paris.

CABRERA BONET, P. (2004): "Vasos cerámicos de importación de lujo del Mediterráneo oriental y central", La vajilla ibérica en época helenística (siglos IV-III al cambio de era), Madrid, 5-17.

CADARIO, M. (2005): "Frammento di base cilíndrica con Menadi danzanti", en A. BOTTINI (a cura di): Il rito Segreto. Misteri in Grecia e a Roma, Roma, 134.

CASAS, J. M., MERINO, J. Y SOLER, V. (1993): "Noves observacions sobre la cerámica vidriada d'època romana de la vil.la de Tolegassos (Viladamat, Alt Empordà)", Cypsela, X, 129-144.

CORALINI, A. (2001): Hercules domesticus. Immagini di Ercole nelle case della regione vesubiana (I secolo a.C.-79 d.C.), Napoli.

COURBY, F. (1913): "Vases à reliefs appliqués du Musée de Délos", Bulletin de Correspondance Hellénique, 37, 418-442.

COURBY, F. (1922): Les vases grecs à reliefs, Paris.

DOUKELIS PANAIOTIS, N. (1995): “Fantasmes d'un atelier de céramique dans Pella hellénistique: I.M. Akamatis, Clay base moulds from Pella. A contribution to the study of Hellenistic pottery", Dialogues d'Histoire Ancienne, 21 (2), $313-314$.

EDWARDS, G. R. (1956): "Hellenistic Pottery", Small Objects from the Pnyx: 2, Hesperia Supplements, 10, 83-112.

EDWARDS, C. M. (1981): "Corinth 1980: Molded Relief Bowls", Hesperia: The Journal of the American School of Classical Studies at Athens, 50 (2), 189-210.

FALCO, G. (2000): "La Sicilia ed il Mediterraneo orientale in età tardo ellenistica: la testimonianza della ceramica «megarese», RCRF Acta 36, 379-386. 
FERNÁNDEZ OCHOA, C., ZARZALEJOS, M., HEVIA, P. Y ESTEBAN, G. (1994): SISAPO I. Excavaciones arqueológicas en La Bienvenida, Almodóvar del Campo (Ciudad Real), Patrimonio Histórico-Arqueología Castilla-La Mancha, 10, Toledo.

FLOREN, J. (1977): Studien zur Typologie des Gorgoneion, München.

FURTWÄNGLER, A. (1900): Die antiken Gemmen. Geschichte der Steinschneidekunst in Klasischen Altertum, Leipzig-Berlin.

GARCÍA Y BELLIDO, A. (1979): Arte romano. Enciclopedia Clásica I, $2^{\mathrm{a}}$ ed., Madrid.

GARCÍA MERINO, C. (1990): "Nuevas piezas de artesanía romana del bronce en la Meseta: apliques con gorgoneion y candelabrum de Uxama", Boletín del Seminario de Estudios de Arte y Arqueología, 56, 244-256.

GILOTTA, F. (1985): Gutti e askoi a rilievo italioti ed etruschi. Teste isolate, Roma.

GIULIANO, A. (1960): “Gorgone”, Enciclopedia dell'Arte Antica Classica e Orientale, 3, Roma, 882-885

GONZÁLEZ SERRANO, P. (2004): “Copias y copistas: el Neoaticismo", en J. BLÁNQUEZ Y M. RUIZ (eds.): Antonio García y Bellido. Miscelánea, Madrid, 263-292.

GRANADOS GARCÍA, J. O. (1977): “Un vaso de cerámica corintia hallado en la necrópolis romana de las Corts: estudios de cerámica romana barcelonesa", Boletín del Seminario de Estudios de Arte y Arqueología, 43, 395-409.

GRANDJOUAN, C., MARKSON, E. Y ROTROFF, S. I. (1989): Hellenistic Relief Molds from the Athenian Agora, Hesperia Supplements, 23, Athens.

GUSI, F. (1974): “Una pátera italiota con medallón en relieve procedente del poblado ibérico del Castell de Almenara", Cuadernos de Prehistoria y Arqueología Castellonense, I, 119-121.

HAUSER, F. (1889): Die Neuattischen Reliefs, Stuttgart.

HEVIA, P., CORRAL, R. y SIERRA, N. (2007): "Excavación y restitución de las pinturas del viridarium de la Domus de las Columnas Rojas de Sisapo (La Bienvenida, Ciudad Real)", en C. GUIRAL (ed.): Circulación de temas y sistemas decorativos en la pintura mural antigua. Actas del IX Congreso Internacional de la Association Internationale pour la Peinture Murale Antique [AIPMA]. Zaragoza-Calatayud 21-25 septiembre 2004. Zaragoza 2007, 471-474.
HOWE, T. P. (1954): "The Origin and Function of the Gorgon-Head", American Journal of Archaeology, 58 (3), 209-221.

LA ROCCA, E. (1984): L'étá d'oro di Cleopatra. Indagine sulla taza Farnese, Roma.

LABROUSSE, M. (1954): “Céramiques ornées d'Arezzo trouvées à Saint-Bertrand-deComminges", Gallia, 12 (2), 301-321.

LAUMONIER, A. (1973): "Bols hellénistiques à reliefs: un batârd gréco-italien", Bulletin de Correspondance Hellénique. Sup. 1, 253-262.

LAUMONIER, A. (1977): La céramique hellénistique à reliefs, I: Les ateliers “ioniens", Exploration Archéologique de Délos faite par l’École française d'Athènes, 31, Paris.

LAVAGNE, H. (2006): "Une danseuse de calathiscos sur un oscillum néo-attique du nord de la Gaule", Comptes-rendus des séances de l'Académie des Inscriptions et Belles-Lettres, 150 (2), 1067-1107.

LEÓN, P. (1995): Esculturas de Itálica, Sevilla.

LEOTTA, M. C. (2005): "Ceramica ellenistica a rilievo in Italia (c.d. italo-megarese)", en D. GANDOLFI (a cura di): La cerámica e $i$ materiali di età romana. Classi, produzioni, commerci e consumi, Bordighera, 51-58.

LIMC (1981-1997): Lexicon Iconographicum Mythologiae Classicae, 8 vols. Zürich-München.

LUZÓN, J. M. Y LEÓN, P. (1971): "Esculturas romanas de Andalucía", Habis, 2, 233-250.

MACK, R. (2002): "Facing Down Medusa (An aetiology of the gaze)", Art History, 25 (5), 571-604.

MALFITANA, D. (2000): "La ceramica corinzia a rilievo di età romana: primi risultati di una ricerca in corso", RCRF Acta 36, 181-188.

MARABINI, M. T. (1980): "Italo-megarian ware at Cosa", Memoirs of the American Academy in Rome, 34, 165-227.

MÍNGUEZ MORALES, J. A. (1995): “Cerámica engobada romana con decoración de medallones en relieve en Aragón: la forma 81.6587.A", Boletín del Seminario de Estudios de Arte y Arqueología, 61, 145-171.

MOREL, J. P. (1980): "La céramique campanienne: acquis et problémes”. En P. LÉV QUE Y J.P. MOREL (eds.): Céramiques hellénistiques et romaines, Paris, 85-122.

MOSCA, F. (2001): "La forma e la funzione: le coppe megaresi di tipo «mastoide», RCRF Acta 37, 251-255. 
NORDSTRÖM, S. (1961): Los cartagineses en la costa alicantina, Alicante.

OLCINA, M., REGINARD, H. Y SÁNCHEZ, M.J. (1990): Tossal de Manises (Albufereta, Alicante). Fondos Antiguos: lucernas y sigillatas, Alicante.

PAILLIER, J. M. (1982): "Les oscilla retrouvés", Mélanges de l'Ecole française de Rome. Antiquité, 94 (2), 743-822.

PÉREZ BALLESTER, J. (1994): “Asociaciones de laginos, boles helenísticos de relieves y ánforas rodias en contextos mediterráneos (siglos II y I a.C.)", en P. CABRERA, R. OLMOS Y E. SANMARTÍ (eds.): Iberos y griegos: lecturas desde la diversidad, Huelva Arqueológica, 13, II, 345-365.

PONSICH M. (1963): "Les lampes romaines de la Collection Ingres (Musée de Montauban)", Revue archéologique du Centre de la France, 2 (2),100132.

POZO, S. F. (2005): "La vajilla metálica de la provincia Baetica. III. La argentería romana", Antiquitas, 17, 33-56.

PUPPO, P. (1995): Le coppe megaresi in Italia, Roma.

PUPPO, P. (2001): “Nuovi dati sulla produzione di ceramica italo-megarese delle officine di Lapius, Popilius ed Herakleides", RCRF Acta 37, 247-250.

PY, M. (1993 a): "Bols hellénistiques à reliefs", Dictionnaire des céramiques antiques (VIIèmes. av. n. è. - VIIème s. de. n. è.) en Méditerranée Nord-Occidentale (Provence, Languedoc, Ampurdan) [DICOCER], Lattara, 6, 132-133.

PY, M. (1993 b): “Céramique à reliefs d'applique de Calès et productions apparentées", Dictionnaire des céramiques antiques (VIIème s. av. n. è. VIIème s. de. n. è.) en Méditerranée NordOccidentale (Provence, Languedoc, Ampurdan) [DICOCER], Lattara, 6, 144-145.

QUEVEDO, A. (2009): "Los contextos cerámicos de Carthago Noua entre los siglos II y III", en J. M. NOGUERA y M. J. MADRID (eds.): Arx Hasdrubalis. La ciudad reencontrada. Arqueología en el cerro del Molinete, Cartagena, Murcia, 63-72.

REINACH, S. (1970): Répertoire de Peintures Grecques et Romaines, Roma.

RICHTER, G. M. A. (1925): "A Neo-Attic Krater in the Metropolitan Museum of Art", The Journal of Hellenic Studies, 45 (2), 201-209.

RICHTER, G. M. A. (1958): "Was Roman Art of the First Centuries B.C. and A.D. Classicizing?", The Journal of Roman Studies, 48 (1-2), 10-15.
RICHTER, G. M. A. (1959): "Calenian Pottery and Classical Greek Metalware", American Journal of Archaeology, 63 (3), 241-249.

RODRÍGUEZ NEILA, F. (1978-79): “Lucernas romanas expuestas al público en el Museo de Córdoba", Corduba, 7, 3-74.

ROLLEY, C. (1999): La sculpture grecque. La période classique, vol.2, Paris.

ROSCHER, W. H. (1894-1897): Ausführliches Lexikon der Griechischen und Römischen Mythologie, II (Laas-Myton), Hildesheim-New York.

ROSCHER, W. H. (1909-1915): Ausführliches Lexikon der Griechischen und Römischen Mythologie, IV (Qu-S), Hildesheim-New York.

ROTROFF, S. (1982 a): Hellenistic pottery. Athenian and imported moldmade Bowls, Athenian Agora, XXII, Princeton.

ROTROFF, S. (1982 b): "Silver, Glass, and Clay Evidence for the Dating of Hellenistic Luxury Tableware", Hesperia. The Journal of the American School of Classical Studies at Athens, 51 (3), 329-337.

ROTROFF, S. (2006): "The Introduction of the Moldmade Bowl Revisited: Tracking a Hellenistic Innovation", Hesperia. The Journal of the American School of Classical Studies at Athens, 75 (3), 357-378.

SANMARTÍ, E. Y GUSI, F. (1975): "Nuevos materiales procedentes del poblado ibérico del Castell (Almenara)", Cuadernos de Prehistoria y Arqueología Castellonenses, 2, 167-172.

SCHAFER, J. (1968): Hellenistische Keramik aus Pergamon. Berlin.

SCHWABACHER, W. (1941): "Hellenistische Reliefkeramik im Kerameikos", American Journal of Archaeology, 45 (2), 182-228.

SIEBERT, G. (1980): "Les bols à reliefs, une industrie d'art à l'époque hellénistique", Céramiques hellénistiques et romaines, Besançon, 55-83.

SIEBERT, G. (2004): "Les problèmes de l'échelle dans les céramiques grecques à reliefs", Ktema, 29, 1727.

SPITZER, D. C. (1942): "Roman Relief Bowls from Corinth", Hesperia: The Journal of the American School of Classical Studies at Athens, 11 (2), 162192.

THÉBERT, Y. (1991): "Vida privada y arquitectura doméstica en el África romana", en Ph. ARIÈS Y G. DUBY (dir.): Historia de la vida privada 1 . Imperio romano y antigüedad tardía, Madrid. 
THOMPSON, H. A. (1934): "Two Centuries of Hellenistic Pottery", Hesperia: The Journal of the American School of Classical Studies at Athens, 3 (4). The American Excavations in the Athenian Agora: Fifth Report, 311-476.

TOUCHETTE, L. A. (1995): The Dancing maenad reliefs: continuity and change in roman copies, Bulletin of the Institute of Classical Studies, Supp. 62, London.

WALTERS, H. B. (1914): Catalogue of the Greek and Roman Lamps in the British Museum, London.

WEINBERG, S. S. (1949): "Investigations at Corinth, 1947-1948", Hesperia: The Journal of the American School of Classical Studies at Athens, 18 (1), 148-157.

ZARZALEJOS, M., FERNÁNDEZ OCHOA, C. Y HEVIA, P. (2004): "El proyecto Sisapo-La Bienvenida (Almodóvar del Campo, Ciudad
Real). Balance de los trabajos más recientes y nuevas perspectivas de la investigación", Investigaciones Arqueológicas en Castilla-La Mancha 1996-2002, Salamanca, 163-180.

ZARZALEJOS, M., FERNÁNDEZ OCHOA, C. Y HEVIA, P. (2007): “Avance sobre las últimas investigaciones en el yacimiento de La Bienvenida (Almodóvar del Campo, Ciudad real). Nuevos elementos para la puesta en valor de la antigua Sisapo". En J. M. Millán y C. Rodríguez (coords.): Arqueología de Castilla-La Mancha. Actas de las I Jornadas (Cuenca 13-17 de diciembre de 2005), Cuenca, 303-330.

ZARZALEJOS, M., FERNÁNDEZ OCHOA, C. Y HEVIA, P. (2011): Investigaciones arqueológicas en Sisapo, capital del cinabrio hispano (I). La decoración musivaria de la domus de las Columnas Rojas (La Bienvenida, Almodóvar del Campo-Ciudad Real), Madrid. 
